\title{
Penile implant infection prevention part II: device coatings have changed the game
}

\author{
John J. Mulcahy ${ }^{1} \cdot$ Tobias S. Köhler $^{2} \cdot{\text { Lexiaochuan } \text { Wen }^{2} \cdot \text { Steven K. Wilson }}^{3}$
}

Received: 29 May 2020 / Revised: 6 July 2020 / Accepted: 23 July 2020 / Published online: 7 August 2020

(c) The Author(s), under exclusive licence to Springer Nature Limited 2020

\begin{abstract}
The single most important factor in the reduction of penile implant infections has been the infection retardant coatings. Virtually every inflatable penile prosthesis (IPP) sold for the last 15 years in America has been coated and the device infection rate has dropped over $50 \%$ to less than $1 \%$ in experienced implanter practices. The vast majority of penile implants are contaminated with bacteria at time of surgery and the bacteria live within the implant spaces in a quiescent fashion protected by a biofilm secreted by the organisms that makes them impermeable to antibiotics or the body's defense mechanisms. Only very rarely do the bacteria cause a clinical infection. Medicine has no clue why this atypically happens. There are new recommendations for systemic prophylactic antibiotics-a testimonial to the changing face of the bacteria causing device infection. New washout solutions are being utilized and new salvage guidelines are being studied.
\end{abstract}

\section{Introduction}

\section{History of the coated devices}

There is no question that the single most important factor in reducing the rate of infected implants has been the advent of infection retardant coatings. The coatings were introduced in 2001 by American Medical Systems (AMS now owned by Boston Scientific) and 2002 by Mentor (now owned by Coloplast). From 2003 to the present, virtually every inflatable penile prosthesis (IPP) sold in the United States by the two prosthesis manufacturers has been coated with infection preventing substances. The Federal Drug Administration in 2009 cleared AMS to publicize that its coating called InhibiZone ${ }^{\circledR}$ reduced the rate of device infection.

The coatings utilized by the two companies are different. InhibiZone $^{\circledR}$ is a mixture of Rifampin and Minocycline

John J. Mulcahy

johnmulc@gmail.com

1 Department of Urology, University of Alabama, Birmingham, AL, USA

2 Department of Urology, Mayo Clinic, Rochester, MN, USA

3 Department of Urology, Institute for Urologic Excellence, La Quinta, CA, USA applied during the manufacturing process [1]. Elution of the antibiotics into the patient's tissues begins when the components are implanted. The product label of the device specifically cautions against soaking or dipping the components as this will reduce the concentration of the antibiotics (Boston Scientific Corporation, AMS 700 Prescriptive Information 2017). The presence of the dispersed drugs in the implant spaces is meant to prevent colonization of the bacteria that inevitably contaminate the incision that is necessary to implant the device. The dosage of the antibiotics impregnated on the components is quite low when compared to dosages of the antibiotics used systemically to treat active infections in patients. Nehra et al. reported a 6-year comparison using patient information forms (PIF) of 11,064 patients showing significant infection reduction in revision/replacement surgery by using AMS coated devices from $3.7 \%$ to $2.5 \%$ [2]. Wilson et al. reported on 467 patients receiving InhibiZone-coated IPPs compared to his published data of 800 noncoated IPP's. There were no infections of 223 first time implants on non-diabetic patients and 1 infection in 83 diabetics. This compared to 3\% and 8\% infection rates respectively in noncoated devices [3].

Mentor developed a hydrophilic coating covalently bonded to its components that, when water was applied, created a lubricated or slippery surface to inhibit bacterial adherence to the implant. In addition, if immediately before implantation the components are dipped in an aqueous solution containing antibacterial drugs, these drugs bond to 
the implant surfaces. The surfaces of the components will subsequently elute the antibiotics into the tissue spaces. These eluted antimicrobials decrease the rate of bacterial colonization in the surgical wound [4]. Utilizing PIF data for 11 years on 36,391 patients from Coloplast, Serefoglu et al. showed significant reduction of device infection from $4.6 \%$ to $1.4 \%$ with the use of hydrophilic coated devices [5]. Eid and Wilson reported 704 coated devices from both companies and compared the infection rates with 132 noncoated devices. Infection rates dropped significantly from $5.3 \%$ to $2 \%$. There was no significant difference in the two manufacturer's infection rates and the Coloplast devices were only dipped in saline without antimicrobials [6].

The use of infection retardant coatings has drastically reduced the incidence of clinical infections e.g. neither Köhler nor Wilson has seen a single infection in a first time, nondiabetic implant patient since the advent of the coated devices. Despite the outstanding performance of the coatings in reducing infection, Boston Scientific (BSci) still produces uncoated components in its AMS 700 lines. These are sold outside the United States at lower prices than the InhibiZone ${ }^{\circledR}$ coated components and can also be used in patients allergic to Rifampin or Tetracycline. BSci also recently launched a new uncoated semi-rigid prosthesis for the treatment of erectile dysfunction (ED). It is regrettable that the company chose to manufacture the new prosthetic device without an anti-infective coating as malleables are frequently used as space holders during a salvage rescue operation for infection and the ability to tailor antibiotics to specific organism cultures seems ideal [7].

Coloplast also markets a semi-rigid rod prosthesis that possesses the infection retardant hydrophilic coating. To their credit, Coloplast globally does not sell any prosthesis used for ED without the proprietary infection retardant capable coating. A new company, Rigicon, is expected to debut sales of both a malleable and IPP in the United States soon. Both their devices appear to feature a hydrophilic coating meant to retard infection.

\section{What we know and do not know about penile implant infections}

Conservative management of device infection is rarely successful. Extirpation of the foreign bodies (implant components) is invariably required for eradication of the offending organisms. What differentiates device infections from other infections in the body and makes them so difficult to treat with antimicrobials alone is the formation of biofilm. Further complicating the picture of device infection prevention is the fact that the protective biofilm occurs quite quickly—within $48 \mathrm{~h}$ (Fig. 1) [8,9].

The bacteria are inoculated into the implant spaces at the time of surgery. The bugs come from the operating room team, from the patient's skin or from breaks in surgical preparation or execution. We believe every implant procedure is contaminated with these organisms $[9,10]$. These bacteria are called planktonic as they swim unprotected in the implant spaces like plankton in the sea (Fig. 2a). Costerton et al. envision a "race for the surface" where the bacteria multiply and try to affix themselves to the surfaces of the implant components [8]. Contemporaneously, the host tries to kill the organisms with macrophages and the peri-operative administered systemic antibiotics. If the bacteria succeed in attaching to the surface of the implant, they multiply quickly. The microcolonies then secrete a matrix formation that is defined as biofilm [9-12]. The biofilm, which resembles slime, is heterogeneous both in space and over time, with development of nutrient and water channels for sustenance of the bacteria (Fig. 2b). Bacteria living in biofilm remain active but have reduced growth rates and commonly undergo genetic transformation which may alter their responsiveness to antimicrobials. Biofilm promotes resistance to antibiotics as it takes up to 1000 times the dose of an antimicrobial needed to kill unprotected planktonic forms [11]. Biofilm also confounds the standard methods of culture; the typical swab method does not pierce the slime so unless some of the bacteria have become planktonic, the culture can yield no growth

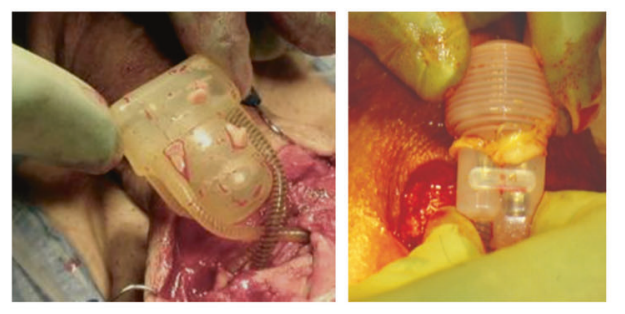

A. Biofilm on pumps explanted for mechanical failure.
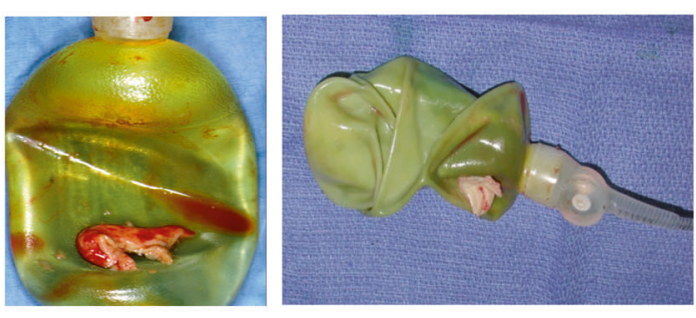

B. Biofilm on reservoirs explanted for mechanical failure.

Fig. 1 Biofilm on implant components. a Biofilm on pumps explanted for mechanical failure. b Biofilm on reservoirs explanted for mechanical failure. 


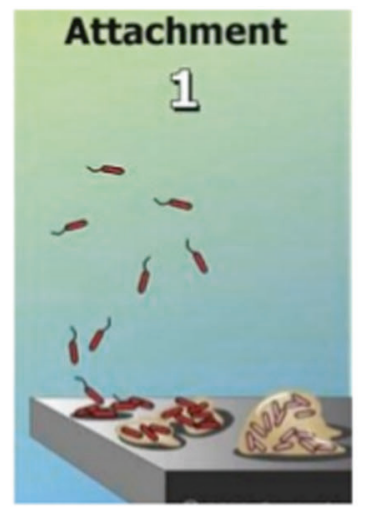

A. Free-floating (planktonic) bacteria: individuals attaching to device surface.

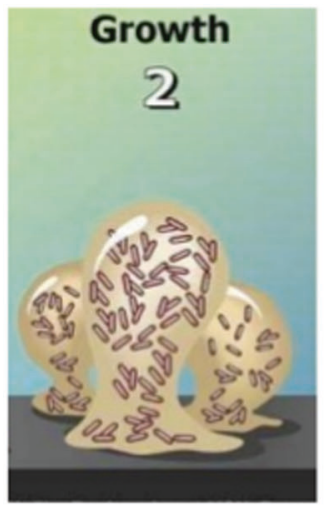

B. After multiplication \& biofilm production, now a sessile state functioning as a community.

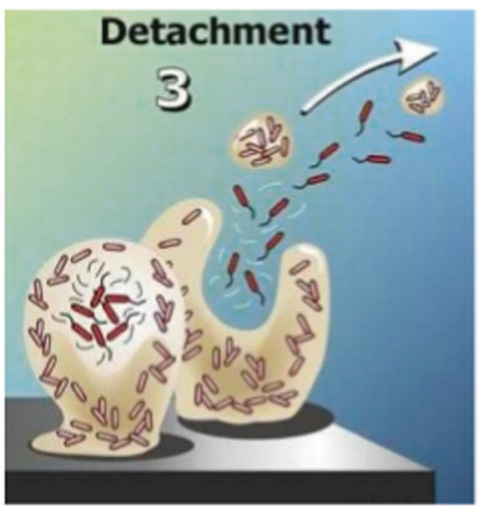

C. Very rarely bacteria leave the community and cause clinical infection.

Fig. 2 Stages of biofilm formation. a Free-floating (planktonic) bacteria: individuals attaching to device surface. b After multiplication \& biofilm production, now a sessile state functioning as a community. c Very rarely bacteria leave the community and cause clinical infection.

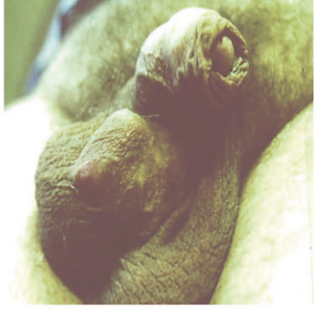

A. Pump stuck to skin.

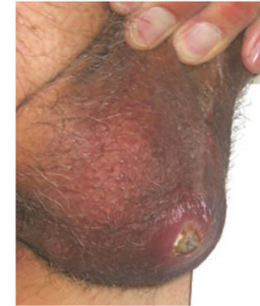

B. Erosion of pump.

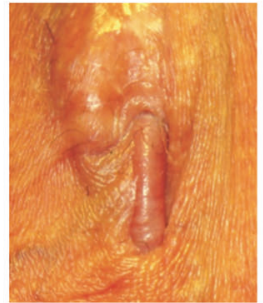

C. Tubing stuck to skin.

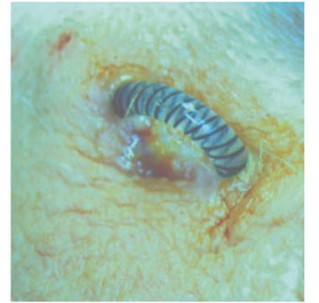

D. Erosion of tubing, serous drainage.

Fig. 3 Skin organism implant infections. All were salvaged. a Pump stuck to skin. b Erosion of pump. c Tubing stuck to skin. d Erosion of tubing, serous drainage.

despite visible biofilm and multiple species of viable bacteria within the slime $[12,13]$

For the last 15 years, Henry has been the lead author of a multicenter group (including Wilson's) producing a series of papers which showed the majority of penile implant patients have organisms residing in the implant spaces despite the patient having no clinical signs of device infection. When these patients undergo a revision operation for noninfectious reasons, organisms and their associated biofilm can be seen on the component surfaces (Fig. 1a, b) visibly or with an electronic microscope on virtually every patient [14]. Many times, organisms can be cultured from the implant spaces and capsule [15] even though the patient is totally asymptomatic. Ciftci et. al. compared swab cultures of coated and noncoated devices at revision surgery for reasons other than infection. They noted that the bacterial growth was significantly less on coated implants at revision surgery than noncoated ones [16]. The overriding question of all experts is, "if every implant is contaminated with bacterial growth protected by biofilm, why do so few devices actually present with a clinical infection?" (Fig. 2c) All interested parties from microbiologists to implant surgeons, PhD's to MD's are baffled by this question!

A follow-up question is easier to ponder, "if the infection retardant coatings diminished device infection rate, how did this occur?" Our best guess would be that the coatings diminished the overall rate of infections by significantly reducing the clinical infections caused by coagulase negative Staphylococci (CNS). These skin organisms, such as Staphylococcus epidermidis and Staphylococcus lugdunensis caused $75 \%$ of the infections in the era of the noncoated implants [17]. Indeed, these skin bacteria were the specific bull's eye of the AMS InhibiZone coating when it was developed 19 years ago [1]. These CNS were also one of the targets in formulating the optimum dips for the Coloplast device 9 years ago [18]. These nosocomial infections present late in the clinical course as mild local infections confined to the implant spaces. The patient has a component stuck to the skin (Fig. 3a-c), a sinus tract draining serous fluid (Fig. 3d) and is not in a lot of 


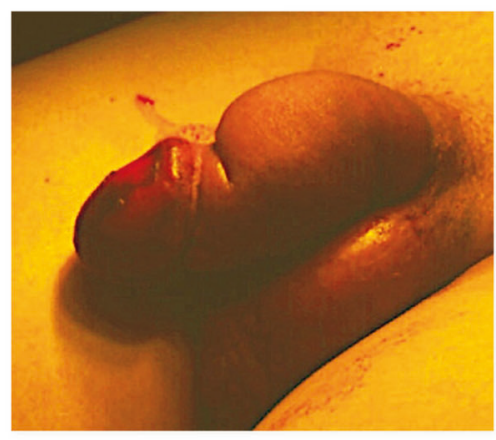

A. Septic 3 weeks post implant. Organism is Pseudomonas.

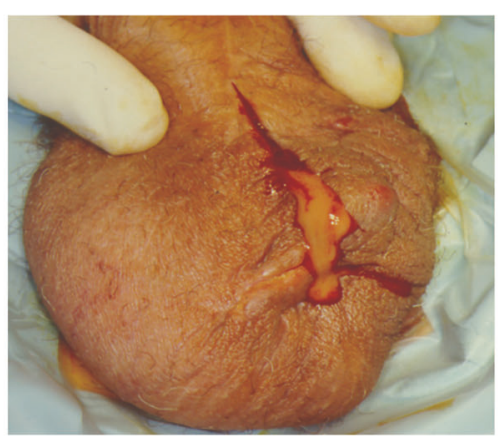

B. Gross purulence, high fever. Organism is enterococcus.

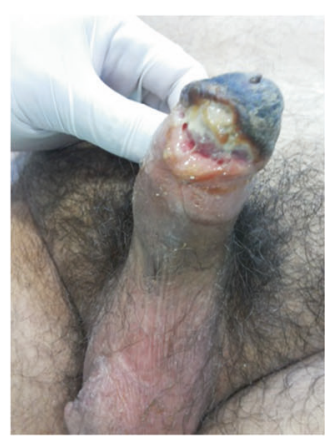

C. Glans necrosis, fever Organism is Staphylococcus aureus.

Fig. 4 Toxic implant infections. a Septic 3 week post implant. Organism is Pseudomonas. b Gross purulence, high fever. Organism is enterococcus. c Glans necrosis, fever. Organism is Staphlococcus aureus.

discomfort. The incidence of this formerly very common "local" presentation has been reduced to $25 \%$ over the last two decades of the coated device availability. The majority of today's very rare device infections $(0.46 \%$ in Eid's series [6]) present with a much more toxic "systemic" clinical picture; the patients have rapid onset of symptoms with fever, purulent drainage and are constitutionally sick (Fig. 4). The organisms cultured are more virulent pathogens such as Methicillin Resistant Staphylococcus Aureus (MSRA) and Enterobacter aerogenes [19]. A recent multicenter study by Gross et al. of 227 clinically infected coated IPP showed a high incidence of anaerobic bacteria, Candida and MSRA infections. Predictably, despite toxic clinical presentation there was no growth on $1 / 3$ of the patients swab cultures [20].

It stands to reason that the infection retardant coatings have reduced the clinical infections caused by the weak skin organisms that do not cause mischief in any other clinical setting than presence of an implant. The same organisms plague hip, knee, and breast prosthetic implanters [21]. Bacteria are introduced into the implant spaces during the time the incision is open. This is usually around $1 \mathrm{~h}$ and rarely more than two for a penile implant. All the efforts of the implanting surgical team is to reduce the bacterial inoculum. Careful skin preparation with alcohol based prep solutions, double gloves changed often, copious irrigation of the wound, avoiding component contact with the skin, and rapidly completed surgery; all are aimed at decreasing the number of bacteria remaining in the wound when it is closed after device implantation. It stands to reason that the maximum bolus of antibiotics eluting off the device is desired in the first 2 or $3 \mathrm{~h}$. Longterm elution likely offers no benefit as the biofilm is protective of bacterial demise within the first $48 \mathrm{~h}$ after wound closure $[8,9]$.
In our future coatings or dips, should we target the new more pathogenic bacteria and fungi? Absolutely a good idea [22]. Unfortunately, it is difficult for the authors of this workshop to believe the relatively weak concentration of antibiotics dispersed by the coatings being meaningful in the face of a MSRA, Pseudomonas or Enterococcus contamination. It seems the easy targets, the wimpy skin bacteria, have largely been contained. The new and very tough targets, the toxic bacteria, may require other measures for infection prevention. After all, during in vitro studies of zones of inhibition created by strips of implant surfaces coated with the infection retardants, the toxic bacteria were quite resistant to the dosage of the dispersed antimicrobials $[1,16,18,22]$.

\section{Use of systemic antibiotic prophylaxis}

In 2008, American Urological Association guidelines were published for using prophylactic antibiotics for a number of urologic procedures [23]. These guidelines contained a small section on antibiotic use associated with prosthetic insertion. They were based on orthopedic literature for artificial joint placement and general surgery studies on mesh inguinal herniorrhaphy, as no substantial series on their use in urologic prosthetic surgery was available. It was recommended that systemic vancomycin and gentamicin be started one hour prior to the incision and be continued for up to $24 \mathrm{~h}$ post operatively and not beyond that point. A third-generation cephalosporin could be substituted for vancomycin, if deemed appropriate. A survey of urologists frequently placing prosthetic devices revealed that a strong majority also used oral antibiotics, usually sulfamethoxazole-trimethoprim (Bactrim ${ }^{\circledR}$, Septra $^{\circledR}$, Cotrim $^{\circledR}$, etc), for 5-14 days after surgery [24]. A study examining nearly 11,000 penile implants found that the 


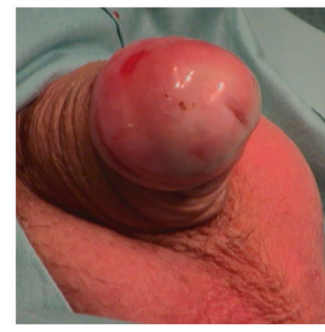

A. Small shrunken penis after IPP removal for infection.

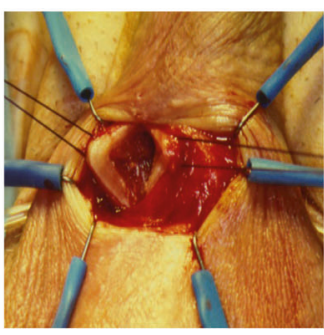

B. Normal cavernosal tissue.

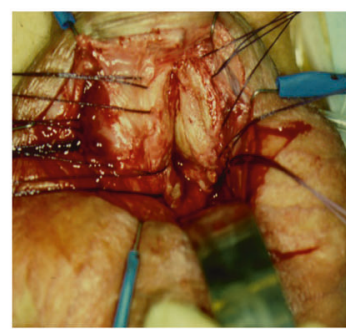

C. Corporal fibrosis.

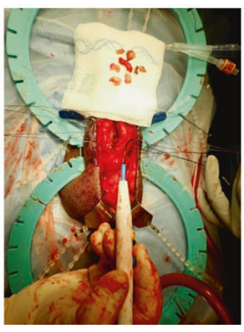

D. Excavation of corporal scar tissue necessary for IPP.

Fig. 5 Aftermath of IPP Infection. a Small shrunken penis after IPP removal for infection. b Normal cavernosal tissue. c Corporal fibrosis. d Excavation of corporal scar tissue necessary for IPP.

infection rate was the same whether or not postoperative oral antibiotics were used [25]. More recently, however, a study of nearly 300,000 patients undergoing facial and plastic reconstructive surgery showed a definitive protective effect of a short course of postoperative oral antibiotic prophylaxis in preventing surgical site infection [26]. The debate persists about post IPP antibiotic use; enthusiasts emphasize the devastating nature of implant infection while naysayers speak to the avoidance of antibiotic resistance. A poll of the senior authors shows Mulcahy and Wilson do not prescribe post-op antibiotic prophylaxis, but Köhler persists.

A recent large series of penile implant infections from 25 centers and involving 153 positive cultures found that the combination of vancomycin, piperacillin-tazobactam, and an antifungal such as fluconazole would be effective against $100 \%$ of the organisms found on culture. Only $86 \%$ of those organisms would have been sensitive to a vancomycin-gentamicin combination [20]. This study, which was retrospective to 2002 and includes the antibiotic coated implant era, reinforces the concept that current penile implant infections involve a more virulent type of organism.

\section{Treatment of an infected penile implant}

Signs and symptoms that an implant has clinically significant infection are prolonged pain over device components, progressive fixation of the pump to the scrotal wall (tethering) (Fig. 3a), a part of the device visible through the skin (Fig. 3b, d), and purulent drainage from the wound (Fig. 4b), especially when accompanied by cellulitis and which increases when a part of the prosthesis is compressed. When an infection is highly suspect, the entire device should be explored and removed. Leaving a part of the device such as a difficult to retrieve reservoir or the input tube sleeve on the AMS 700 series runs the risk of perpetuating the infection. The entire device should be considered infected, as organisms can easily spread along the tubing. The patient and his urologist should decide whether to leave the implant out and return at a later date for reinsertion, or perform a salvage or rescue maneuver, washing the wound with a series of antiseptic solutions, changing to a fresh operating field, and inserting a new implant at the same procedure [27]. The benefit of the salvage maneuver is maintaining most of the erectile length and providing an easier cylinder insertion.

If the reinsertion is performed months later when the inflammation subsides, the surgeon is faced with the aftermath of penile implant infection; cylinder insertion into scarred corporal bodies (Fig. 5c, d) will be more difficult and loss of erectile length in the range of 2 in. will occur (Fig. 5a) [28]. Only about $25 \%$ of patients will return for implant reinsertion at a later date, although they were originally so highly motivated to continue sexual activity as to undergo prosthesis placement. Historically the original salvage rescue operation was titled delayed salvage; the infected device was removed, drains through which antibiotic irrigations were administered for 48-72 $\mathrm{h}$ were placed, and the patient was returned to the operating room after 2-3 days for new sterile implant placement [29]. It was found to be no more successful than immediate salvage, was more costly, and the patient had increased morbidity. The original Mulcahy salvage series of over 100 patients showed a success rate of $84 \%$. The failures seemed to include those whose symptoms appeared within 2 months of the implant placement, were caused by virulent organisms, and were accompanied by purulence and cellulitis. Many urologists would exclude patients with this combination from consideration for a salvage procedure, but a series of four such patients, treated with systemic vancomycin and gentamicin for 3 days prior to removal of the infected implant with simultaneous salvage procedure, showed uniform success in eradicating the infection [30]. The organisms cultured were MRSA in two cases and Pseudomonas and Serratia in the other two cases. We believe improvement of the cellulitis would indicate that the systemic antibiotics being used are effective against the organisms involved in the infection and that the salvage procedure should prove to be successful. The systemic antibiotics 
sterilize the tissues outside the implant spaces, the washings sterilize the implant cavities. Current information would indicate that the triple combination of vancomycin (Vancocin ${ }^{\circledR}$ ), piperacillin-tazobactam $\left(\right.$ Zosyn $\left.^{\circledR}\right)$, and fluconazole (Diflucan ${ }^{\circledR}$ ) would be more appropriate in treating a suspected implant infection before wound culture results are available [20].

The original salvage series used antibiotic, hydrogen peroxide, and betadine irrigations attempting to sterilize the infected implant cavities [31]. These irrigations have been used for 25 years without challenge due to the high success rate of $84 \%$. A recent extensive study of the orthopedic literature for artificial joint infection management focused on the irrigations used by that specialty. The authors found that hydrogen peroxide showed no benefit over betadine and could be cytotoxic. In addition, very dilute betadine left in the tissues for 3 min seemed to be more effective than the more concentrated form [32]. Chlorhexidine may be a better irrigating solution for eradicating infection than betadine, but literature supporting this concept is insufficient. The question is still unsolved whether any irrigation solution should contain antiseptic substances, or would saline irrigations suffice during a salvage procedure. Dr. Francois Eid, a prolific penile prosthesis implanter, is prohibited by his hospital from using antibiotic additions to irrigations. He commonly uses only saline for his "wash out" and dip for the Coloplast prosthesis [6]. He has related to our first author that he has also had success using saline irrigations during a few salvage procedures which he has performed. The lavage of the irrigating solution washing out the cavities may be all that is needed. As Mulcahy opines, "dilution is the solution to pollution."

In the original salvage series whatever brand or type of infected implant the patient presented with, that type and brand was used as the replacement device [30]. The vast majority were three-piece inflatable implants. A multicenter study assessed the success of using a semi-rigid rod implant as the replacement device for the infected implant in 58 salvage procedures with 54 successes (93\%) [7]. This approach avoids the need to place a new reservoir and pump, the latter in a usually macerated scrotum, and shortens the operative time. About one third of the patients opted for an upgrade to a three-piece inflatable implant at a later date. Although penile implant infections can be treated successfully with ultimately gratifying results, prophylaxis with systemic antibiotics, copious wound irrigations, antibiotic coated devices, avoidance of prolonged operative times, and other measures are extremely important [33].

\section{Conclusion}

We know a great deal about penile implant infections but our previously held beliefs about incidence, prevention, and therapies are changing. The infection retardant coatings have drastically decreased the incidence but the rare infections that occur are caused by different organisms than occurred during the noncoated era. These generally more toxic bugs require changing prophylactic antibiotic recommendations and salvage indications. Lavage of implant spaces is important in preventing revision infections, but the antiseptic chemicals in the irrigants are in question. Finally, the biggest mystery of penile implant infection is why quiescent organisms living in communities in the implant spaces very infrequently become planktonic again and cause clinical infection. Or, could the rare infections be caused by breaks in surgical technique and have nothing to do with the biofilm protected bugs in the implant spaces? These are questions that will undoubtedly propel the field of prosthetic urology with innovative targets for additional preventative and therapeutic strategies.

\section{Compliance with ethical standards}

Conflict of interest JJM: Consultant: Boston Scientific, Coloplast. TSK: Consultant: Boston Scientific, Coloplast. LW: Nothing to disclose. SKW: Consultant: AMT, Coloplast, International Medical Devices. Lecturer: Boston Scientific. Stockholder: NeoTract

Publisher's note Springer Nature remains neutral with regard to jurisdictional claims in published maps and institutional affiliations.

\section{References}

1. Brock G, Bochinski D, Mahoney CB. InhibiZone treatment: the first antibiotic treatment impregnated into the tissue-contacting surface of an inflatable penile prosthesis. J Urol. 2001;165:A1047.

2. Nehra Ajay, Carson CC, Chapin AK, Ginkel AM. Long-term infection outcomes of 3-piece antibiotic impregnated penile prostheses used in replacement implant surgery. J Urol. 2012; 188:899-903.

3. Wilson SK, Zumbe J, Henry GD, Salem EA, Delk JR, Cleves MA. Infection reduction using antibiotic-coated inflatable penile prosthesis. Urology. 2007;70:337-40.

4. Hellstrom WJG, Hyun JS, Human L, Sanabria JHA, Bivalacqua TJ, Leungwattanakij S. Antimicrobial activity of antibioticsoaked, Resist-coated Bioflex. Int J Imp Res. 2003;15:18-21.

5. Serefoglu EC, Mandava SH, Gokce A, Chouhan JD, Wilson SK, Hellstrom WJ. Long-term revision rate due to infection in hydrophilic-coated inflatable penile prostheses: 11-year follow-up. J Sex Med. 2012;8:2182-6.

6. Eid JF, Wilson SK, Cleves M, Salem EA. Coated implants and the "no touch" surgical technique decreases risk of infection in inflatable penile prosthesis implantation to $0.46 \%$. Urology. 2012;79:1310-15.

7. Gross MS, Phillips EA, Balen A, Eid JF, yang C, Simon R, et al. The malleable implant salvage technique: infection outcomes after Mulcahy salvage procedure and replacement of inflatable penile prosthesis with malleable prosthesis. J Urol. 2016;195:694-8.

8. Costerton JW, Stewart DS, Greenberg EP. Bacterial biofilms: A common cause of persistent infection. Science. 1999;284:318-28.

9. Wilson SK, Costerton JW. Biofilm and penile prosthesis infections in the era of the coated implants: a review. J Sex Med. 2012;9:44-53. 
10. Darouiche RO. Treatment of infections associated with surgical implants. N. Engl J Med. 2004;350:1422-29.

11. Costerton JW, Veeh R, Shritliff M. The application of biofilm science to the study and control of chronic bacterial infections. J Clin Investig. 2003;112:1466-76.

12. Arciola CR, Campossia D, Montanaro L. Implant infections: adhesion, biofilm formation and immune evasion. Nat Rev Microbiol. 2018;16:397-409.

13. Choong S, Whitfield H. Biofilms and their role in infection and urology. BJU Int. 2000;86:935-7.

14. Silverstein AK, Henry GD, Evans B, Pasmore M, Simmons CJ, Donatucci CF. Biofilm formation on clinically non infected penile prostheses. J Urol. 2006;176:1008-11.

15. Henry GD, Wilson SK, Delk JR, Carson CC, Silverstein A, Cleves MA, et al. Penile prosthesis cultures during revision surgery: multicenter study. J Urol. 2004;172:153-6.

16. Ciftci S, Nemut T, Culha MM, Yilmaz H, Ustuner M, Yavuz Y, et al. Non-infected penile prosthesis cultures during revision surgery; comparison between antibiotic coated and non-coated devices. Int Braz J Urol. 2016;42:1183-9.

17. Wilson SK, Delk JR. Inflatable penile implant infection: predisposing factors and treatment suggestions. J Urol. 1995;153:659-61.

18. Wilson SK, Salem E, Costerton JW. Anti-infection dip suggestions for the Coloplast Titan inflatable penile prosthesis in the era of the infection retardant coated implant. J Sex Med. 2011;8: 2647-54.

19. Kava BR, Kanagarajah P, Ayyathurai R. Contemporary revision penile prosthesis surgery is not associated with a high risk of implant colonization or infection: a single-surgeon series. J Sex Med. 2011;8:1540-45.

20. Gross MS, Phillips EA, Carrasquillo RJ, Thornton Amanda, Greenfield JM, Levine LA, et al. Multicenter investigations of the micro-organisms involved in penile prosthesis infection: an analysis of the efficacy of the AUA and EAU Guidelines for penile prosthesis prophylaxis. J Sex Med. 2017;14:455-63.

21. Wilson HB. "No-touch" enhancement significantly reduces the risk of infection-related failure in immediate breast reconstruction. Ann Plast Surg. 2019;82 6S Suppl 5:S410-S416.
22. Lokeshwar SD, Bitran JH, Madhusoodanan V, Kava B, Ramasamy Ranjith. A surgeon's guide to the various antibiotic dips available during penile prosthesis implantation. Cur Urol Rep. 2019;20:11.

23. Wolf JS, Bennett CJ, Dmochowski RR, Hollenbeck BK, Pearle MS, Schaeffer AJ, et al. Best practice policy statement on urologic surgery antimicrobial practice. J Urol. 2008;179:1379-90.

24. Darouiche RO, Bella AJ, Boone TB, Broderick GA, Burnett AL, Carrion R, et al. North American consensus document on infection of penile prosthesis. Urology. 2013;82:937-42.

25. Adamsky MS, Boysen WR, Cohen AJ, Ham S, Dmochowski RR, Faris SF, et al. Evaluating the role of post-operative oral antibiotic administration in artificial urinary sphincter and inflatable penile prosthesis explanation: a nationwide analysis. Urology. 2018;111: 92-98.

26. Olds C, Spataro E, Li K, Kandathil C, Most SP. Postoperative antibiotic use among patients undergoing functional facial plastic and reconstructive surgery. JAMA Facial Plast Surg. 2019;21:491-497.

27. Mulcahy JJ. Long term experience with salvage of infected penile implants. J Urol. 2000;163:481-2.

28. Lopategui DM, Balise RR, Bouzoubaa LA, Wilson SK, Kava B. The impact of immediate salvage surgery on corporeal length preservation in patients presenting with penile implant infections. J Urol. 2018;200:171-7.

29. Knoll LD. Penile prosthesis infection management by delayed and immediate salvage technique. Urology. 1998;52:287-90.

30. Mulcahy JJ. Penile implant infections: prevention and treatment. Curr Urol Rep. 2008;9:487-91.

31. Brant MD, Ludlow JK, Mulcahy JJ. The prosthesis salvage operation: immediate replacement of the infected penile prosthesis. J Urol. 1996;155:155-7.

32. Pan S, Rodriguez D, Thirumavalavan N, Bross MS, Eid JF, Mulcahy J, et al. The use of antiseptic solutions in the prevention and management of penile prosthesis infections: a review of the cytotoxic and microbiological effects of common irrigation solutions. J Sex Med. 2019;16:781-90.

33. Kohler TK, Wen L, Wilson SK. Penile prosthesis prevention part 1: what is fact and what is fiction. Int J Imp Res. 2020. 